\title{
PENGARUH BRAND EXPERIENCE DAN BRAND PERSONALITY TERHADAP CUSTOMER LOYALTY
}

\author{
The Influence Of Brand Experience And Brand Personality On Customer \\ Loyalty (Case Study Smartphone Samsung)
}

\author{
${ }^{1}$ Fithrotudiniyah, ${ }^{2}$ Sri Andriani, ${ }^{3}$ Putri Reno Kemalasari \\ Universitas Teknologi Sumbawa \\ JI. Raya Olat Maras, Moyo Hulu, \\ Kabpaten Sumbawa, Nusa Tenggara Barat. \\ Email: Fithrotudiniyah28@gmail.com
}

\begin{abstract}
Abstrak
Penelitian ini bertujuan untuk mengetahui Pengaruh Brand Experience Dan Brand Personality Terhadap Customer Loyalty Smartphone Samsung (studi pada mahasiswa Universitas Teknologi Sumbawa). Variabel yang digunakan yaitu, Brand Experience, Brand Personality. Populasi adalah seluruh mahasiswa aktif UTS yang menggunakan smartphone samsung dengan sampel sebanyak 100 orang. Instrumen yang digunakan adalah kuesioner dan alat analisis yang digunakan adalah SPSS. Jenis data yakni data primer yang didapat dari hasil pengisian kuesioner dengan penilaian skala likert 4 poin. Uji prasyarat meliputi uji normalitas, uji heteroskedastisitas, dan uji multikolinearitas serta teknik analisis yang digunakan yakni analisis regresi linear berganda. Hasil penelitian ini menunjukan bahwa variabel brand experience berpengaruh terhadap customer loyalty dan brand personality berpengaruh terhadap Customer loyalty. Kata kunci :Brand Experience, Brand Personality, Customer Loyalty.
\end{abstract}

\begin{abstract}
This study aims to determine the effect of Brand Experience and Brand Personality on Samsung Smartphone Customer Loyalty (study at Sumbawa University of Technology students). The variables used are, Brand Experience, Brand Personality. The population is all active UTS students who use Samsung smartphones with a sample of 100 people. The instrument used was a questionnaire and the analytical tool used was SPSS. The type of data is primary data obtained from the results of filling out the questionnaire with a 4-point Likert scale assessment. The prerequisite tests include normality test, heteroscedasticity test, and multicollinearity test and the analysis technique used is multiple linear regression analysis. The results of this study indicate that brand experience variables affect customer loyalty and brand personality effect on customer loyalty.
\end{abstract}

Keywords :Brand Experience, Brand Personality, Customer Loyalty.

\section{PENDAHULUAN}

Di era globalisasi dan modern saat ini dengan perkembangan teknologi dan informasi semakin berkembang pesat dari tahun ke tahun tedapat berbagai macam penemuan produk dibidang teknologi informasi dan komunikasi. Teknologi komunikasi dikembangkan tidak hanya untuk keperluan berkomunikasi, tetapi juga keperluan aktualisasi diri.Saat ini berbagai macam merek smartphone telah beredar di pasar ponsel Indonesia, sampai pada kancah internasional. Menurut data yang dirilis oleh International Data Corporation (IDC), selama dua quartal terakhir terdapat lima merek smartphone di dunia dengan pangsa pasar dan tigkat pertumbuhan penjualan tertinggi diantara merek lainya yaitu Samsung, Huawei, Apple, Xiomi, Oppo. Berikut adalah data pangsa pasar dari kelima merek tersebut: 


\section{Tabel 1.1 Pangsa Pasar Smartphone di}

Seluruh Dunia dan Pertumbuhan

Tahun 2018-2019

\begin{tabular}{|c|c|c|c|}
\hline \multicolumn{4}{|c|}{ Canalys Smartphone Market Pulse: Q3 } \\
\hline Company & $\mathbf{2 0 1 9 Q 3}$ & $\mathbf{2 0 1 8 Q 3}$ & $\begin{array}{c}\text { Annual } \\
\text { Growth }\end{array}$ \\
\hline Samsung & $22.4 \%$ & $20.4 \%$ & $+11 \%$ \\
\hline Huawei & $19.0 \%$ & $14.9 \%$ & $+29 \%$ \\
\hline Apple & $12.3 \%$ & $13.4 \%$ & $-7 \%$ \\
\hline Xiomi & $9.2 \%$ & $9.6 \%$ & $-3 \%$ \\
\hline Oppo & $9.1 \%$ & $8.6 \%$ & $+6 \%$ \\
\hline Others & $28.0 \%$ & $33.0 \%$ & $-14 \%$ \\
\hline Total & $\mathbf{1 0 0 . 0} \%$ & $\mathbf{1 0 0 . 0} \%$ & $\mathbf{+ 1} \%$ \\
\hline
\end{tabular}

Sumber : www.canalys.com October 2019.

Berdasarkan tabel 1.1 dapat disimpulkan bahwa Samsung memiliki pangsa pasar paling tinggi di antara merek-merek smartphone lainya, Samsung adalah merek smartphone yang dijadikan objek penelitian karena Samsung merupakan smartphone yang sudah hadir dan di kenal oleh masyarakat sebagai (ponsel) cerdas yang berasal dari Korea Selatan yang saat ini menjadi salah satu jawara dalam persaingan bursa pasar smartphone.

Masyarakat Indonesia cenderung menggunakan produk yang dapat memberikan banyak kepuasaan dan manfaat, serta pengalaman yang dirasakan menjadi tolak ukur pada prilaku kesetiaan konsumen (customer loyalty). (Tjiptono, 2011), Oleh karena itu customer loyalty menjadi salah satu fokus utama bagi perusahaan untuk dijaga dan dibina hubungannya agar tetap terjalin dengan baik, mengingat dengan mudahnya konsumen berpindah dari pemakai satu merek produk ke merek produk yang lain (Sciffman dan Kanuk, 2010).

Kesetiaan tidak terbentuk dalam waktu singkat tetapi melalui proses belajar dan berdasarkan hasil pengalaman dari konsumen itu sendiri (Kotler \& Amstrong 2012).Pengalaman yang dirasakan oleh konsumen akan berpengaruh pada customer loyalty dengan melakukan pembelian ulang juga merekomendasikan kepada orang sekitar.
Pengalaman terhadap merek (brand experience) memiliki peranan penting dalam membentuk customer loyalty terhadap merek, tidak hanya berpengaruh pada loyalitas, brand experience dapat melibatkan ikatan emosional konsumen, dimana konsumen yang menyenangi merek ditandai dengan gairah dan pengaruh positif, dan dapat dianggap sebagai komponen aktif kepuasan

Menurut Ruthet al., (2011) menyatakan bahwa generasi $Y$ (Milenial) adalah konsumen yang tingkat loyalitasnya pada merek sangat rendah. Generasi $Y$ adalah generasi yang cenderung sering menggunakan smarpthone dengan berbagai merek, dengan jumlah lebih dari $25 \%$ populasi di dunia, generasi $Y$ merupakan generasi yang sangat bersosialisasi, ahli teknologi dan yang lebih penting, generasi $Y$ tumbuh dengan teknologi (Nusair et al., 2015). Kesetiaan tidak terbentuk dalam waktu singkat tetapi melalui proses belajar dan berdasarkan hasil pengalaman dari konsumen itu sendiri (Kotler \& Amstrong 2012).Didasarkan pada penelitian yang dilakukan oleh Fajariah et al, (2016) bahwa kesetiaan merek pada gen $Y$ relatif rendah. Maka dari itu objek penelitian yang ingin saya teliti adalah mahasiswa pengguna smartphone Samsung di Universitas Teknologi Sumbawa.Maka peneliti tertarik melakukan penelitian dengan mengambil judul penelitian "Pengaruh Brand Experience dan Brand Personality Terhadap Prilaku Kesetiaan Pelanggan Atau Customer Loyalty". Dengan tujuan untuk menguji ulang seberapa besar pengaruh pengalaman merek dan kepribadian merek terhadap perilaku kesetiaan pada konsumen.

\section{RUMUSAN MASALAH}

1. Bagaiamana pengaruh brand experience terhadap customer loyalty pada merek Samsung?

2. Bagaimana pengaruh brand personality terhadap customer loyalty pada merek Samsung?

3. Bagaimana pengaruh brand experience dan brand personality terhadap customer loyalty pada merek Samsung ?

\section{HIPOTESIS PENELITIAN}

Secara empiris, banyak penelitian yang membuktikan bahwa brand experience menimbulkan rasa percaya diri untuk menjadi customer yang loyal. Menurut Brakus dan Keller, (2009) Konsep yang berkembang adalah brand experience digunakan untuk memahami konsep, konsep kepercayaan merek dan loyalitas merek. Brand experienceakan masuk ke memori jangka panjang dalam pikiran konsumen yang mempengaruhi kepuasan konsumen dan 
loyalitas yang akhirnya berperan penting pada pembentukan tingkah laku konsumen, sehingga dapat berpengaruh kepada customer loyalty terhadap sebuah merek.

$\mathrm{H} 1$ : Brand experience berpengaruh signifikan terhadap customer loyalty

Selanjutnya penelitian yang menunjukan bahwa upaya untuk mencari pelanggan baru jauh lebih mahal, kerena perusahaan harus mengeluarkan biaya promosi dan iklan yang jumlahnya jauh lebih besar (lin, 2010). Untuk itu, perusahaan yang ingin mempertahankan pelanggannya, akan menjadikan merek produknya memiliki keunggulan kompetitif yang dapat merepresentasikan karakter dari merek tersebut, karena menurut "Govers dan Schoormans" Brand Personality yang sesuai dengan personality mereka dan hal tersebut akan meningkatkan customer loyalty terhadap merek.

$\mathrm{H} 2$ : Brand personality berpengaruh signifikan terhadap customer loyalty

Kesetiaan pelanggan pada sebuah merek dapat menghasilkan word-of mouth (WOM) yang positif, dan WOM merupakan unsur penghalang bagi pesaing, serta membuat perusahaan lebih kuat untuk mengahadapi persaingan, dan menghasilkan penjualan lebih banyak (Khani et al, 2013). Kesetiaan terhadap sebuah merek khususnya customer loyalty tentunya tidak hanya dilakukan dengan mengandalkan hanya satu faktor melainkan pembentukan loyalitas tersebut harus dilaksanakan dengan mengkolaborasikan beberapa faktor yang mempengaruhi loyalitas secara positif (Lin, 2010).

H3: Brand experience dan brand personality berpengaruh signifikan secara simultan terhadap customer loyalty.

\section{DEFINISI OPERASIONAL}

1) Brand experience (X1)

Brand experience didefinisikan sebagai sensasi, perasaan, kognisi, dan tanggapan konsumen yang ditimbulkan oleh merek, terkait rangsangan yang ditimbulkan oleh desain merek, identitas merek, komunikasi pemasaran, orang dan lingkungan merek tersebut dipasarkan. Brakus (2009) menyatakan indikator dalam brand experience antara lain sebagai berikut :
a) Sensorik
b) Afeksi
c) Perilaku
d) Intelektual
2) Brand Personality (X2)

Brand personality sekumpulan sifat psikologis manusia yang menyebabkan respon yang relatif konsisten dan tahan lama terhadap rangsangan lingkungan termasuk prilaku pembelian. Idealnya merek juga mempunyai personality dan konsumen mungkin memilih merek yang kepribadianya sesuai dengan mereka. Kotler dan Keller (2018) menyatakan indikator dalam brand personality :

a) ketulusan

b) kegembiraan

c) kecakapan

d) up-to-date

e) ketangguhan

3) Customer loyalty adalah komitmen yang dipegang secara mendalam untuk membeli atau berlangganan bagi produk atau jasa tertentu di masa depan meskipun ada pengaruh situasi dan usaha pemasaran yang berpotensi menyebabkan peralihan perilaku (Oliver dalam Kotler dan Keller 2018).

Menurut Griffin (2012) menyatakan bahwa customer loyalty dapat dilihat berdasarkan karakteristik sebagai berikut:

1) Melakukan pembelian ulang

2) Merekomendasikan kepada orang lain

3) Tidak mudah terpengaruh dengan produk lain

4) Membeli diluar lini produk atau jasa (servis)

\section{METODOLOGI}

Penelitian ini merupakan jenis penelitian yang menggunakan metode penelitian kuantitatif yaitu mendeskripsikan Pengaruh brand experience dan brand personality terhadap costumer loyalty di Universitas Teknologi Sumbawa. Data yang di gunakan dalam penelitian ini adalah data primer. Populasi dalam penelitian ini adalah mahasiswa aktif yang menggunakan smartphone Samsung mulai dari angkatan 2016 - 2019 dengan jumlah populasi belum di ketahui yang berada di Universitas Teknologi Sumbawa.Sampel dalam penelitian ini menggunakan teknik purposive sampling pada mahasiswa yang menggunakan smartphone Samsung di Universitas Teknologi Sumbawa. Menurut Sugiyono, (2018) Purposive sampling adalah teknik pengumpulan sampel dengan pertimbangan tertentu. Pengumpulan data penelitian ini adalah dengan menggunakan angket atau kuesioner.Teknik yang digunakan untuk uji validitas pada penelitian ini adalah membandingkan antara nilai rhitung dengan nilai rtabel dengan tarif signifikan 0,05 . Jika rhitung $\geq$ rtabel (dengan sig. 0,05) maka instrumen atau item-item pertanyaan berkorelasi signifikan terhadap skor total (dinyatakan valid).Cara yang digunakan untuk menguji reliabilitas kuisioner adalah dengan menggunakan rumus koefisien Cronbach Alpha, penggujian ini dilakukan dengan bantuan program SPSS 22. Dasar pengambilan keputusannya sebagai berikut: 
a) Jika nilai koefisien reliabilitas $\geq 0,6$ maka instrumen yang diuji memiliki reliabilitas yang baik atau reliable atau terpercaya.

b) Jika nilai koefisien reliabilitas $\leq 0,6$ maka instrumen yang diuji tersebut tidak reliable.

\section{HASIL DAN PEMBAHASAN}

\subsection{Hasil Uji Normalitas}

Interpretasi yang digunakan dalam uji normalitas yaitu sig. $\geq 0,05$ diartikan data berdistribusi normal. Berdasarkan hasil pengujian normalitas menggunakan uji kolmogorovSmirnov.

Berdasarkan dari hasil uji normalitas menggunakan metode Kolmogorov-Smirnov didapatkan hasil signifikansi dari uji normalitas sebesar 0,076 dimana hasil tersebut lebih besar dari taraf signifikansi 0,05 , sehingga dapat disimpulkan bahwa uji normalitas pada penelitian ini adalah terdistribusi normal.

\section{Hasil Uji Heteroskedastisitas}

Jika Heteroskedastisitas dalam penelitian ini dengan melakukan uji Glejser atau Absolute Residual dari data. Apabila hasil regresi untuk masing-masing variabel menunjukkan hasil signifikan diatas tingkat kepercayaan atau signifikansi $5 \%$ maka model regresi tidak mengandung adanya heteroskedastisitas.

\section{Tabel 4.4 Hasil Uji Heteroskedastisitas}

\begin{tabular}{|c|c|c|c|c|c|}
\hline \multicolumn{6}{|c|}{ Coefficients $^{\mathbf{a}}$} \\
\hline & \multicolumn{2}{|c|}{$\begin{array}{l}\text { Unstandardiz } \\
\text { ed } \\
\text { Coefficients }\end{array}$} & $\begin{array}{c}\text { Standardi } \\
\text { zed } \\
\text { Coefficie } \\
\text { nts } \\
\end{array}$ & & \\
\hline Model & B & $\begin{array}{c}\text { Std. } \\
\text { Error }\end{array}$ & Beta & $\mathrm{t}$ & Sig. \\
\hline $\begin{array}{c}\text { (Consta } \\
\mathrm{nt})\end{array}$ &,- 502 & 1,112 & &,- 452 & ,653 \\
\hline Brand & & & & & \\
\hline $\begin{array}{c}\text { Experien } \\
\text { ce }\end{array}$ &,- 046 &, 050 &, 113 &,- 918 &, 361 \\
\hline Brand & & & & & \\
\hline $\begin{array}{c}\text { Personali } \\
\text { ty }\end{array}$ &, 007 & ,046 & ,019 & ,156 &, 876 \\
\hline
\end{tabular}

a. Dependent Variable: Abs_RES

Sumber: Data diolah peneliti, 2019.
Berdasarkan hasil uji glejser setelah transformasi data pada tabel diatas menunjukan nilai signifikan dari brand experience sebesar 0,361 lebih dari 0,05 , variabel brand personality sebesar 0,876 artinya variabel independen dalam penelitian ini memiliki nilai segnifikan lebih besar dari 0,05 . Sehingga dapat disimpulkan bahwa dalam penelitian ini tidak ada indikasi heteroskedastisitas.

\section{Hasil Uji Multikolinearitas}

Menurut Ghazali, (2013) ada tidaknya multikolinieritas dapat dilihat dari besarnya Variance Inflation Factor (VIF) dan nilai Tolerance Value. Yaitu jika tolerance value $\geq$ 0,10 atau VIF $\leq 10$ : terjadi multikolinearitas.

\section{Tabel 4.5 Hasil Uji Multikolinearitas}

\begin{tabular}{|l|l|l|l|}
\hline Variabel & Tolerance & VIF & Keterangan \\
\hline $\begin{array}{l}\text { Brand } \\
\text { Experience }\end{array}$ & 0.655 & 1,526 & $\begin{array}{l}\text { Tidak terjadi } \\
\text { multikolinearitas }\end{array}$ \\
\hline $\begin{array}{l}\text { Brand } \\
\text { Personality }\end{array}$ & 0.655 & 1,526 & $\begin{array}{l}\text { Tidak terjadi } \\
\text { multikolinearitas }\end{array}$ \\
\hline
\end{tabular}

Sumber: Data diolah peneliti,2019.

Berdasarkan dari hasil uji multikolinearitas bahwa variabel brand experience (X1) dengan nilai tolerance $0.655 \geq 0.10$ dan nilai VIF $1,526 \leq$ 10 , variabel brand personality (X2) dengan nilai tolerance $0,655 \geq 0.10$ dan nilain VIF 1,526 $\leq 10$, Maka dapat disimpulkan bahwa semua variabel bebas tidak terjadi multikolinearitas.

\subsubsection{Brand Experience Berpengaruh Terhadap Customer Loyalty \\ Berdasarkan hasil kuisioner dari delapan} pernyataan kepada 100 responden yang menggunakan skala 1-4 memiliki rata-rata dengan skor 3 pada indikator Samsung yang memiliki persentasi tertinggi sebesar 3,23\% pada pernyataan Samsung memiliki cara promosi yang konsisten. Hasil yang diperoleh menunjukan bahwa Samsung dapat memberikan pengalaman kepada konsumen seperti Samsung melakukan promosi melalui iklan yang menarik, pelayanan karyawan Samsung yang baik dan sopan, Samsung memberikan garansi produk yang sesuai sehingga pengalaman yang diberikan dapat membentuk sikap loyal terhadap Samsung. Sikap loyal konsumen dapat mengakibatkan rasa percaya diri dan keyakinan dalam menentukan pilihan. Pilihan yang diputuskan oleh mahasiswa dapat membentuk perilaku konsumen yaitu memilih Samsung 
sebagai pilihan dalam kehidupan sehari-hari. Sehingga dengan keputusan konsumen memilih Samsung dalam kehidupan sehari-hari akan terjadi loyalitas konsumen. Hasil penelitian ini selaras dengan penelitian Wismiarsi et al (2015), yang menyatakan bahwa brand experience berpengaruh tetapi tidak signifikan terhadap customer loyalty.

\subsubsection{Brand Personality Berpengaruh Terhadap Customer Loyalty}

Dengan rata-rata skor 4 pada indikator Samsung dengan persentasi nilai tertinggi sebesar 3,25\% pada pernyataan Samsung tetap menjaga eksistensinya di pasaran. Hasil yang diperoleh menunjukan bahwa personality merek Samsung dapat dikatakan sesuai dengan yang diinginkan dan dibutuhkan konsumen. Ciri khas yang dimiliki oleh Samsung seperti Samsung memiliki daya saing yang kuat, Samsung memiliki citra yang baik, Samsung memiliki inovasi pada design dan warna produk, hal itulah yang dapat mempengaruhi persepsi konsumen dan menjadi faktor terbentuknya sikap untuk loyal terhadap Samsung. Hal ini terjadi karena brand personality produk Samsung dapat sesuai dengan keinginan dan kebutuhan konsumen serta itulah yang dapat dikatakan sesuai dengan kepribadian konsumen di Universitas Teknologi Sumbawa. Sehingga dapat disimpulkan bahwa brand personality mempunyai pengaruh terhadap costumer loyalty smartphone Samsung. Hasil penelitian ini selaras dengan penelitian Wismiarsi et al (2015), yang menunjukan terdapat pengaruh yang signifikan antara brand personality oleh konsumen terhadap customer loyalty.

\subsubsection{Brand Experience dan Brand Personality Berpengaruh Terhadap Customer Loyalty}

Hasil analisis yang diperoleh variabel brand experience dan brand personality ialah kedua variabel bebas mempunyai pengaruh yang signifikan secara bersama-sama terhadap variabel terikat customer loyalty. Dilihat pada hasil uji hipotesis secara simultan menunjukan bahwa nilai probabilitas 0,000 lebih kecil dari nilai signifikansi 0,05 yang berarti hipotesis alternatif diterima dan hipotesis nol ditolak, artinya jika hipotesis alternatif diterima maka kedua variabel independen memiliki pengaruh ke arah yang sama secara bersama-sama terhadap variabel dependen. Pengaruh ke arah yang sama dapat di artikan jika brand experience dan brand personality mengalami besarnya peningkatan maka customer loyalty juga akan meningkat atau semakin besar tingkat loyalitas konsumen. Pengaruh secara bersama-sama dapat dilihat dari hasil kuisioner pada indikator pernyataan Samsung dengan rata-rata skor 3 dengan bobot nilai 3,09\% pada pernyataan saya akan kembali membeli Samsung.

Hasil yang diperoleh menunjukan bahwasanya pengalaman merek Samsung serta kepribadian Samsung memberikan kesan positif tentang Samsung dalam memasarkan produknya untuk menarik minat konsumen, menjaga eksistensinya dalam persaingan smartphone, melakukan banyak inovasi dalam bersaing, menunjukan citra yang baik, memanfaatkan technologi dalam melakukan strategi marketing serta kelebihan produk yang ditunjukan oleh Samsung dapat sesuai dengan apa yang diinginkan oleh konsumen. Hal itulah yang akhirnya dapat membentuk suatu sikap yang positif dari seorang konsumen yang berdampak pada loyalitas konsumen. Hasil penelitian ini selaras dengan penelitian Wismiarsi et al (2015), yang menyatakan bahwa variabel brand experience dan brand personality berpengaruh signifikan secara bersama-sama terhadap customer loyalty.

\section{KESIMPULAN}

Berdasarkan analisis dan pembahasan hasil penelitian yang telah dilakukan, maka dapat ditarik kesimpulannya sebagai berikut:

1) Brand experience menunjukan adanyapengaruh tetapi tidak signifikan terhadap customer loyalty, maka dapat di simpulkan bahwa pengalaman merek Samsung yang dirasakan oleh konsumen di Universitas Teknologi Sumbawa dapat membentuk perilaku kesetiaan dalam menggunakan smartphone Samsung.

2) Brand personality memberikan pengaruh yang signifikan terhadap customer loyaltysmartphone Samsung. Dengan hasil ini menunjukan bahwa brand personality merek samsung mampu menyesuaikan dengan kepribadian konsumen yang menghasilkan suatu sikap setia dalam diri konsumen untuk menggunakan satu merek smartphone yang telah dipilih oleh mahasiswa Universitas Teknologi Sumbawa.

3) Brand experience dan brand personality memiliki pengaruh yang signifikan secara bersama-sama terhadap customer loyalty. Dengan hasil ini menunjukan bahwa kedua variabel independen berpengaruh secara simultan terhadap variabel dependen dalam menghasilkan sebuah akibat dari 
perilaku konsumen yang menggunakan smartphone samsung.

\section{DAFTAR PUSTAKA}

Aaker, David A. (1997)Manajemen Ekuitas Merek. Spektrum. Jakarta, Indonesia.

Aaker, Jennifer L. (1997). Dimensions Of Brand Personality. Journal Of MarketingResearch Vol (34) August 1997. (347-356).

Akin, M., (2017)." The Impacts Of Brand Personality On Brand Loyalty: A Research On Automobile Brands In Turkey" International Journal Of Marketing Studies.

Arikunto, S. (2010). Prosedur Penelitian Suatu Pendekatan Praktek. Rineka Cipta. Jakarta.

Arikunto, S. (2013). Prosedur Penelitian Suatu Pendekatan Praktik. Jakarta:Rineka Cipta.

Bambang., Lubis., R., \& Darsono N. (2017). Pengaruh Brand Image, Brand Personality, Brand Experience Terhadap Brand Love Dampaknya Pada Brand Loyalty. Jurnal Perspektif Manajemen Dan Perbankan.

Bawono, A. (2006). Multivariate Analyze Dengan Spss. Salatiga:Stain Salatiga Press.

Bilgihan, A., Nusair, K., Okumus, F., \& Cobanoglu, C. (2015). Applying Flow Theory To Booking Experiences: An Integrated Model In An Online Service Context. Infor- Mation \& Management, 52(6), $668 \mathrm{e} 678$.

Brakus J. J. Schmitt, B.H \& Zarantonello, L. (2009) " Brand Experience: What Is It? How is It Measured? Does It Affect Loyalty.Journal Of Marketing, 52-68.

Bryan, C. \& Dharmayanti, D. (2015). Analisa Pengaruh Brand Experience Terhadap Costumer Loyalty Melalui Brand Trust, Costumer Satisfaction Dan Costumer Intimacy Sebagai Variabel Intervening Pada Kiehl's Surabaya. Jurnal Manajemen Pemasaran Petra.

Choi, Y. G., Ok, C., \& Hyun, S. S. (2011). Evaluating Relationship Among Brand
Experience, Brand Personality, Brand Prestige, Brand Relationship Quality, And Brand Loyalty: An Empirical Study Of Coffeehouse Brands.

Devindiani, E., (2016). Pengaruh Experiental Marketing Terhadap Costumer Satisfaction Serta Dampaknya Pada Costumer Loyalty. Journal Of Business Management And Enterpreneurship Education.

Engel Et Al. (2002). Perilaku Konsumen. Edisi Keenam, Jilid 1. Binarupa Aksara.Jakarta.

Fajariah, Nuraida . (2016). Pengaruh Brand Awareness, Perceived Quality Dan Brand Image Terhadap Brand Loyalty Pada Generasi Y Di Indonesia.Economy Faculty And Business, University Of Brawijaya.

Ghazali, I. (2013). Aplikasi Analisis Multivariat Dengan Program $\mathrm{lbm}$ Spss. Semarang:Badan Penerbit Universitas Diponegoro.

Griffn, Jill. (2012). Customer Loyalty Terjemahan Dwi Kartini Yahya. Jakarta: Erlanga.

Hasan, I. (2003). Pokok-Pokok Materi Statistik 2. Jakarta : Bumi Aksara.

Husein, U. (2009). Metode Penelitian Untuk Skripsi Dan Thesis Bisnis. Edisi Kedua. Jakarta:Raja Grafindo Persada.

Iskandar. (2008). Metodologi Penelitian Pendidikan Dan Sosial (Kuantitatif Dan Kualitatif). Jakarta:Gaung Persada Press.

Khani, S., Imanikhah, S. M., Gheysari, H., Kamali, S. S., \& Ghorbanzadeh, T. (2013). The Relationship Of Appliance Consumer Personality Trait, Brand Personality, Brand Loyalty And Brand Equity In The Mobile Phone Industry. International Journal Of Fundamental Psychology And Social Sciences.

Kosasih, Dadan Ahmad Fadili, Dan Nurul Fadilah, (2013). Pengaruh Perilaku Konsumen Terhadap Keputusan Pembelian Sepeda Motor Yamaha Di Dealer Arista Johar. Jurnal Manajmen. 
Kotler, Philip And Gay Amstrong. (2012). Prinsip-Prinsip Pemasaran. Edisi13.Jilid 1. Jakarta: Erlangga.

Kotler, Philip \& Keller, Kevin Lane. (2012). Marketing Management. Essex: Pearson Education Inc.

Kotler, Philip \& Keller, Kevin Lane. (2018). Marketing Management. Edisi 13, Jilid 1.

Lin, L. Y. (2010). The Relationship Of Customer Personality Trait, Brand Personality And Brand Loyalty: An Empirical Study Of Toys And Video Games Buyers. Journal Of Products And Brand Management.

Mardalis. (2009). Populasi Dan Sampel Penelitian. Retrieved From Http://Triatra.Wordpress.Com

Oliver, R.L. (1999). Whence Consumer Loyalty? Journal Of Marketing, 63(4): 33-44

Prasetijo Ristiyanti . (2005). Perilaku Konsumen. Yogyakarta : Andi.

Rangkuti, Freddy. (2012). The Power Of Brands. Jakarta, Pt Gramedia Pustaka Utama.

Ratnawati, A., \& Lestari, A. (2018). Peran Brand Trust Dalam Memediasi Brand Experience, Brand Personality Dan Brand Community Terhadap Brand Loyalty. Jurnal Ekonomi Bisnis, Vol.19, No.2 185-202.

Ruth, N.B., Parasuraman, A., Hoefnagels, A. Migchels, N. Gruber, T., Loureiro, Y. K., Dan Solnet, D. (2011). Understanding Generation $Y$ And Their Use Of Social Media: A Review And Research Agenda. Thought Leadership Conference On "Connections, Communities, And Collaboration: Service Sustainability In The Digital Age" In Nijmegen.The Netherlands.

Sahin, A., Zehir, C., Kitapci, H. (2011), The Effects Of Brand Experiences, Trust And Satisfaction On Building Brand Loyalty. And Empirical Research On Global Brands, Procedia - Social And Behavioral Sciences.

Schmitt, B. (2007). Experiental Marketing. The Free Press New York.
Sciffman And Kanuk (2010) Schiffman, L. G., Kanuk, L. L. (2010). Consumer Behavior, New Jersey: Prentice Hall.

Sugiyono. (2015). Metode Penelitian Pendidikan (Pendekatan Kuantitatif, Kualitatif, Dan $R \& D)$. Bandung: Alfabeta.

Sugiyono. (2018). Metode Penelitian Kuantitatif Kualitatif Dan R\&D. Bandung: Alfabeta.

Sujarweni, W. V. (2015). Metodologi Penelitian Ekonomi Dan Bisnis. Yogyakarta: Pustaka Baru Press.

Sung, Y., J. Kim And J. Hyuok. (2010). Thepredictive Roles Of Brand Personality On Brand Trust And Brand Affect: A Study Of Korean Consumer. Journal Of International Consumer Marketing.

Tanzeh, A. (2012). Pengantar Metode Penelitian. Yogyakarta: Teras.

Tjiptono, Fandy Dan Gregorius Chandra. (2011). Service, Quality \& Satisfaction. Yogyakarta: Andi.

Tjiptono, Fandy \& Gregorius Chandra, (2012). Pemasaran Strategik. Yogyakarta.

Venkateswaran, P. S. (2011). A Study On Brand Personality Dimensions Andbrand Loyalty Toward Raymond Brand. Journal Of Marketing And Communication.

Wijaya, T. (2009). Analisis Data Penelitian Menggunakan Spss. Yogyakarta: Universitas Atmajaya.

Wiratma S. (2015). Metedelogi Penelitian Bisnis Dan Ekonomi. Yogyakarta: Pustaka Baru Press.

Wismiarsi, T., (2015). Behavioural Loyalty:Apakah Dipengaruhi Brand Personality Dan Brand Experience?. Jurnal Manajemen Dan Bisnis Sriwijaya.

Yasri., Rahmiati\& Sylvia, D., (2014). Pengaruh Komunitas Merek Dan Personalitas Merek Terhadap Loyalitas Merek Oriflame Di Kota Padang. Jurnal Kajian Manajemen Bisnis.

Zhang, J. And Y. He. (2013). Key Dimention Of Brand Value Co-Creation And Its Impacts Upon Customer Perception And 
JURNAL MANAJEMEN DAN BISNIS VOL. 02 NO.2 2019

Jurnal.uts.ac.id

Brand Performance.Journal Of Marketing And Business.

Zarantonello, L., \& Schmitt, B. H. (2010). Using The Brand Experience Scale To Profile Consumers And Predict Consumer Behaviour. Journal Of Brand Management.

Zeithmal, Valarie A, Et.Al Dan Mary Jo Bitner. (2013). Service Marketing. Irwin Mcgraw Hill, Boston. New York: Usa.

Https:/Www.Canalys.Com/Newsroom/Globalq3s martphonemarket. Diakses Pada Tanggal 4 November 2019. 